\title{
Applications of 2-Aminophenol derived Schiff Base Transition Metal Complexes. A Review
}

\author{
Benjamin Chibuzo Ejelonu \\ Department of Chemical Sciences, Adekunle Ajasin University, Akungba Akoko Ondo State. Nigeria \\ benjamin.ejelonu@aaua.edu.ng
}

\begin{abstract}
The literature survey showed that the chelating Schiff base ligands derived from 2-aminophenol compounds encompass a highly remarkable class of compounds having a wide range of applications in clinical, biochemical and physiological activities. The involvement of metal complex formation in normal life processes has led to reviews from medical chemistry research, Inorganic chemistry research and several field of chemistry research. The literature survey showed that the chelating Schiff base ligands derived from 2-aminophenol compounds encompass a highly remarkable class of compounds having a wide range of applications in clinical, biochemical and physiological activities. Many Schiff base complexes with transition metals have drawn wide attention because of their diverse biological and pharmaceutical activities The aim of this review is to draw the attention of coordination chemist to focus research on application of schiff base transition metal complexesderived from 2-amino phenol for it has several important application in biological system.
\end{abstract}

Keywords: physiological, 2-aminophenol, Schiff base, Metal chelates

\section{Introduction}

Coordination chemistry employs Schiff bases which have achieved prime importance in this era. The extensive studies have been conducted on complexation of Schiff bases with metals due to the attractive physicochemical properties of metal complexes and broad range of utilization in various areas of science. Such types of complexes have paved the way for exploration and findings of a variety of metal complexes in recent years.

Transition metal complexes of 2-aminophenol based Schiff bases have been the subject of extensive investigation because of their wide use in various fields. These Schiff base complexes have wide applications in biological field, as antidepressants, antimicrobial, antitumor, antiphlogogistic, nematocide, and other medicinal agents have been reported based on these compounds. Furthermore these complexes have good catalytic role in many reactions. The data available for 2-aminophenol based Schiff bases in literature embracesvery wide and diversified subjects, comprising vast areas of organo-metallic compounds and multiple aspects of bioinorganic chemistry.

Abdallah et al [1] prepared a new Schiff base (H2L) ligand is via condensation of o-phthaldehyde and 2-aminophenol. The metal complexes of $\mathrm{Cr}(\mathrm{III}), \mathrm{Mn}(\mathrm{II}), \mathrm{Fe}(\mathrm{II}), \mathrm{Fe}(\mathrm{III}), \mathrm{Co}(\mathrm{II}), \mathrm{Ni}(\mathrm{II}), \mathrm{Cu}(\mathrm{II})$ and $\mathrm{Zn}$ (II) with the ligand are prepared in good yield from the reaction of the ligand with the corresponding metal salts. Then they have screened their parent Schiff base and its eight metal complexes against two fungal and two bacterial species. With respect to antifungal activity, the parent Schiff base and four metal complexes inhibited the growth of the tested fungi at different rates. $\mathrm{Ni}(\mathrm{II})$ complex is the most inhibitory metal complex, followed by Cr(III) complex, parent Schiff base then Co(II) complex. With regard to bacteria, only two of the tested metal complexes (Mn(II) and $\mathrm{Fe}(\mathrm{II})$ )weakly inhibit the growth of the two tested bacteria.

Omima M.I. Adly[2] synthesized metal complexes of Ni(II), $\mathrm{Co}(\mathrm{II}), \mathrm{Cd}(\mathrm{II}), \mathrm{VO}(\mathrm{IV})$ and UO2(VI) as well as several $\mathrm{Cu}(\mathrm{II})$ salts with a tridentate $\mathrm{O} 2 \mathrm{~N}$ donor Schiff base ligand (H2L), by condensation of 5-acetyl4-hydroxy-2H-1,3-thiazine-2,6(3H)-dione with 2-aminophenol.

The antimicrobial activities of the synthesized compounds were tested in vitro against the sensitive organisms Staphylococcus aureus as Gram positive bacteria, Proteus vulgaris as Gram negative bacteria and Candida albicans as fungus strain, and the results are discussed. The investigation of antibacterial and antifungal screening data revealed that most of the synthesized complexes were found to possess various antimicrobial activities toward all microorganisms, while the ligand did not show any activity toward all types of microorganism, suggesting greater lipophilic nature of the complexes than the free ligand.

Ayman A. Abdel Aziz et al [3] worked on the reactions of acetate salts of $\mathrm{M}(\mathrm{II})(\mathrm{M}=\mathrm{Mn}, \mathrm{Co}, \mathrm{Ni}, \mathrm{Cu}$ and $\mathrm{Zn}$ ) with $\mathrm{N}$-salicylidene-o-aminophenol (saphH2) in ethyl alcohol afforded new four coordinated complexes. The new complexes have been tested for their abilities to catalyze aerial oxidation of benzaldehyde to benzoic acid. The in vitro antimicrobial activities of the new complexes were studied against the bacteria: $S$. aureus (gram $+\mathrm{ve}$ ) and E. coli (gram -ve) and fungi: A. flavus and C. albicans. The data has shown that Mn(II) 
complex show the higher antibacterial and antifungal activity, while other complexes showed no to moderate activity. The results have been compared with some known antibiotics.

Mixed ligand complexes derived from 2,6-pyridinedicarboxaldehydebis( $o$-hydroxyphenylimine),6pyridinedicarboxaldehydebis ( $p$ hydroxyphenylimine) (1ry ligands) and 2-aminopyridne 2ry ligand). IR spectra show that the Schiff bases are coordinated to the metal ions in a terdentate manner with NNN donor sites of the pyridine- $N$ and two azomethine- $N$. While 2 aminopyridine coordinated to the metal ions via its pyridine- $N$. Magnetic and solid reflectance spectra are used to infer the coordinating capacity of the ligand and the geometrical structure of these complexes are found to be octahedral. The biological activity of the two Schiff base ligands (L1 and L2), their mixed ligand complexes and chloroamphenicol (as a standard compound) were tested against bacteria because bacteriums can achieve resistance to antibiotics through biochemical and morphological modifications. The organisms used in the present investigations included Staphylococcus aureus and Bacillus subtillis (as gram positive bacteria) and Pseudomonas aereuguinosa and Escherichia coli (as gram negative bacteria). The diffusion agar technique was used to evaluate the antibacterial activity of the synthesized mixed ligand complexes. The activity of the two Schiff base ligands and their mixed ligand complexes increases as the concentration increases because it is a well-known fact that concentration plays a vital role in increasing the degree of inhibition [4].

Radhika Pallikkavil et al [5] prepared terephthalaldehyde on reaction with 2- aminophenol and 2 aminothiophenol and it yielded a new series of polydentate Schiff's base ligands (H2La and H2Lb). Dibasic tetradentate coordination of the compounds in their [M2L2] complexes [M $=\mathrm{Ni}(\mathrm{II}), \mathrm{Cu}(\mathrm{II})$ and $\mathrm{Zn}(\mathrm{II})]$ has been established on the basis of analytical and spectral data.

Bibhesh K. Singh et al [6] developed a new Schiff base 2-aminophenol-pyrrole-2- carboxaldehyde and its $\mathrm{Zn}(\mathrm{II}), \mathrm{Cd}(\mathrm{II}), \mathrm{Sn}(\mathrm{II})$ and $\mathrm{Pb}(\mathrm{II})$ complexes. The bio-efficacy of the ligand and their complexes has been examined against the growth of bacteria in vitro to evaluate their antimicrobial potential. The ligand and complexes exhibited high activity against E. coli $(100 \mathrm{ppm})$ and others show very effective against $\mathrm{S}$. aureus $(100 \mathrm{ppm})$ bacteria. The zinc complex showed better activity than other metal complexes for both microorganisms.

Amr A. Ibrahim et al [7] derived metal complexes of novel Schiff base (HL) ligand, prepared via condensation of 4-aminoantipyrine and 2-aminophenol. The synthesized ligand, in comparison to its metal complexes is screened for its antibacterial activity against bacterial species, Escherichia coli, Pseudomonas putida, Exiguobacterium acetylicum and Bacillus simplex. The activity data show that the metal complexes to be more potent/antibacterial than the parent Shciff base ligand against one or more bacterial species.

$\mathrm{Ru}(\mathrm{III})$ Schiff base complexes of the type $[\mathrm{RuX}(\mathrm{EPh} 3) \mathrm{L}](\mathrm{X}=\mathrm{Cl} / \mathrm{Br} ; \mathrm{E}=\mathrm{P} / \mathrm{As} ; \mathrm{L}=$ dianion of the Schiff bases were derived by the condensation of 1,4-diformylbenzene with $o$-aminobenzoic acid/oaminophenol/ o-aminothiophenol in the 1:2 stoichiometric ratio) from the reactions of [RuX3(EPh3)3] with appropriate Schiff base ligands in benzene in the 2:1 stoichiometric ratio[8].

Three pathogenic microbials were used to test the biological potential of the Schiff bases and their ruthenium(III) complexes. They were (i) Escherichia coli, (ii) Aeromonas hydrophilla and (iii) Salmonella typhi. The antibacterial activity of the compound was determined by disc diffusion method. The results showed that the ruthenium chelates are more toxic compared to their parent ligands against the same microorganisms under identical conditions. The toxicity of ruthenium chelates increases on increasing the concentration. The increase in the antibacterial activity of metal chelates may be due to the effect of the metal ion on the normal cell process. Though the complexes possess some significant activity, it could not reach the effectiveness of the standard drug Streptomycin.

VD Bhatt et al [9], dinuclear complexes from salicylaldehyde and 2-aminophenol with $\mathrm{Cu}$ (II), $\mathrm{Ni}$ (II) \& Co (II) were obtained by new synthetic route and characterized. The presence of two coordinated water molecules was detected both from elemental analysis and thermo gravimetric analysis. The molecular ion peaks in the mass spectra also supported the formation of dinuclear complexes. The magnetic studies of the complexes revealed ferromagnetic and antiferromagnetic coupling in the complexes under present investigation. Finally, the molecular mechanical method used for energy minimization corroborated the proposed structure of the complexes. This first report on the synthesis of dinuclear complexesvia novel route is capable of opening a new era in the preparation of complexes with lot more variations.

Masoud Salavati-Niasari et al[10], new square-planar $\mathrm{Mn}(\mathrm{II}), \mathrm{Cu}(\mathrm{II}), \mathrm{Ni}(\mathrm{II})$ and $\mathrm{Co}(\mathrm{II})$ complexes of a tetradentate Schiff-base ligand "bis(2-hydroxyanil)benzil, H2[habenzil]; have been prepared. The results suggest that the symmetrical Schiff-base is a bivalent anion with tetradentate $\mathrm{N} 2 \mathrm{O} 2$ donors derived from the phenolic oxygen and azomethine nitrogen. The formulae was found to be [M(habenzil)] for the 1:1 non-electrolytic complexes. Alumina-supported metal complexes (ASMC; [M(habenzil)/Al2O3]) catalyze the oxidation of cyclohexene with tert-buthylhydroperoxide (TBHP) and H2O2. Oxidation of cyclohexene with TBHP gave 2cyclohexene-1-one, 2-cyclohexene-1-ol and 1-(tert-butylperoxy)-2- cyclohexene whereas, oxidation with $\mathrm{H} 2 \mathrm{O} 2$ 
resulted in the formation of cyclohexene oxide and cyclohexene-1,2-diol. Manganese(II) complex supported on alumina "[Mn(habenzil)]/A12O3" shows significantly higher catalytic activity than other catalysts.

Krishnankutty et al[11] derived Phenylazo- and thiazolylazo-2,4-pentanediones on reaction with 2aminophenol and 2-aminothiophenol yielded a new series of polydentate Schiff's base ligands. Four new polydentate Schiff base ligands have been prepared by the condensation of 3-(phenylazo)- and 3-(2thiazolylazo)-2,4-pentanediones with 2 aminophenol and 2-aminothiophenol.

Analytical, IR, 1H-NMR and mass spectral data revealed a 1:2 product (H2tap) with 3- (2thiazolylazo)-2,4-pentanedione and 2-aminophenol in which both carbonyl groups of the dione are involved in the Schiff base formation. In all other cases, 1:1 condensation products (H2pap, H2pat and H2tat) are formed. The analytical, physical and spectral data of the [ML] com plexes of $\mathrm{Ni}(\mathrm{II}), \mathrm{Cu}(\mathrm{II})$ and $\mathrm{Zn}$ (II) showed dibasic tetradentate $\mathrm{N} 2 \mathrm{O} 2$ coordination involving the azomethine nitrogens and the phenolic oxygens of $\mathrm{H} 2 \mathrm{tap}$. All the other ligands functioned as dibasic tridentates where the imine and hydrazone nitrogens and the $\mathrm{O}-\mathrm{H} / \mathrm{S}-\mathrm{H}$ groups are coordinated in their 1:1 metal chelates.

Sayudevi et al[12] prepared two new Schiff bases containing olefinic linkages have been synthesized by condensing ortho-substituted aromatic amines with dicinnamoylmethane under specified conditions. The existence of these compounds predominantly in the intramolecularly hydrogen bonded keto-enamine form has been well demonstrated from their IR, 1H NMR and mass spectral data. Details on the formation of their complexes with $\mathrm{Ni}(\mathrm{II}), \mathrm{Cu}(\mathrm{II})$ and $\mathrm{Zn}$ (II) and their nature of bonding are discussed on the basis of analytical and spectral data.

Anita Sharma et al[13] have synthesized transition metal complexes which is derived from 2-((3-(4 fluorophenyl)-1-phenyl-1H-pyrazol-4-yl) methylene amino) phenol. The most probable stereochemistry of the synthesized $\mathrm{Cu}(\mathrm{II}), \mathrm{Ni}$ (II) and $\mathrm{Co}(\mathrm{II})$ complexes was given by its magnetic moment. The effective magnetic moments of $\mathrm{Cu}$ (II), Co (II) and Ni (II) complex were measured in DMF solution at room temperature. Thermogram of $\mathrm{Cu}$ - complex indicated the total weight loss of $79.9 \%$ up to $1000^{\circ} \mathrm{C}$. Thermogram of $\mathrm{Co}$ complex indicated the total $92.5 \%$ up to $1000^{\circ} \mathrm{C}$. The thermo gravimetric analysis (TGA) provides authentic information regarding the presence of water molecules in the coordination sphere of the all complexes.

Akila et al[14] prepared a new binuclear Schiff base metal complexes of $\mathrm{Cu}(\mathrm{II}), \mathrm{Ni}(\mathrm{II})$ and $\mathrm{Co}(\mathrm{II})$ with a new hexadentate $\mathrm{N} 4 \mathrm{O} 2$ ligand derived from p-phenylenediamine, glyoxal/ biacetyl and 2-aminophenol. Biological activity of the ligand and a series of its metal complexes [Cu(II), $\mathrm{Ni}(\mathrm{II})$ and $\mathrm{Co}(\mathrm{II})$ complexes] were screened for antibacterial activity against staphylococcus aureus $(\mathrm{G}+\mathrm{ve})$, Eschericia coli $(\mathrm{G}-\mathrm{ve})$ and $\mathrm{Klebsilla}$ pneumonia(G-ve) by disc diffusion method. It is known that the chelation tends to make the ligand acts as more powerful and potent bacterial agent. On chelation, the ligand with the $\mathrm{N}$ and $\mathrm{O}$ donor system might have inhibited enzyme production, since enzyme which requires a free $-\mathrm{OH}$ group for their activity appear to be especially susceptible to deactivation by the ions of the complexes. The chelation also reduces the polarity of central metal ion because of partial sharing its + ve charge with the donor group and possible $\pi$ electron delocalization within the whole chelate ring. This increases the nature of central metal ion which favors its permeation through lipid layers of the cell membrane. This increased lipophilicity enhances the penetration of complexes into the lipid membrane and blocks the metal binding sites in enzymes of microorganisms. These $\mathrm{Cu}(\mathrm{II}), \mathrm{Ni}(\mathrm{II})$ and $\mathrm{Co}(\mathrm{II})$ complexes also disturb the respiration process and thus block the synthesis of proteins, which restrict further growth of the organisms.

Some new transition metal complexes of $\mathrm{Mn}(\mathrm{II}), \mathrm{Co}(\mathrm{II}), \mathrm{Ni}(\mathrm{II}), \mathrm{Cu}(\mathrm{II})$ and $\mathrm{Zn}(\mathrm{II})$ with Schiff base ligand (HL) derived from condensation of vanillin with 2-aminophenol was synthesized in alcoholic medium[15].

The antimicrobial results revealed that the ligand showed moderate activity against Escherichia coli, Staphylococcus aureus, Streptococcus pyogenes and Bacillus subtilis with maximum zone of inhibition of $25 \mathrm{~mm}$ against Escherichia coli. Mn(II) show considerable activity at all concentrations against Escherichia coli, Salmonella typhi, Staphhlococcus aureus and Bacillus subtilis with maximum zone of inhibition of $30 \mathrm{~mm}$ at $300 \mathrm{mg} / \mathrm{ml}$ against Salmonella typhi. Co (II) showed very low activities against Klebsilla pneumoniae, Steptococus pyogenes and Bacillus subtilis with zone of inhibition range within 07- 08, 08-12 and 07-10 respectively. Ni (II) complex was found to be reasonably active against Escherichia coli, salmonella typhi, Staphylococcus aureue, Streptococcus pyogenes and Bacillus subtilis with highest zone of inhibition of $36 \mathrm{~mm}$ against Salmonella typhi. $\mathrm{Cu}(\mathrm{II})$ complex exhibited only moderate inhibitory activity range between $07-18 \mathrm{~mm}$ against Salmonella typhi, Klebsella pneumonia Streptococcus pyogenes and Bacillus subtilis. It is evidenced from the result that $\mathrm{Zn}$ (II) complex did not produce any inhibitory zones against all the Gram-negative bacteria used, but it was found to be effective at all concentrations, against all the Gram-positive bacteria. 


\section{Conclusion}

In this review, an overview of the effects of 2-aminophenol and its derivatives which have shown promising results had been discussed. Schiff bases have been widely explored for biological applications. However, the biological activity of this class of compounds deserves further investigation. A number of reports disclosing the effects of the 2-aminophenol Schiff bases on the clinical interest have recently been increasing. This kind of Schiff base compounds have been shown to be promising leads for the design of more efficient antimicrobial agents.

\section{References}

[1]. M. Sayed. Abdallah, Gehad G. Mohamed, M.A. Zayed, Mohsen S. Abou El-Ela, Spectroscopic study of molecular structures of novel Schiff base derived from o-phthaldehyde and 2-aminophenol and its coordination compounds together with their biological activity, Spectrochimica Acta Part A, 73, 2009, 833-840

[2]. M.I Omima. Adly, Characterization, molecular modeling and antimicrobial activity of metal complexes of tridentate Schiff base derived from 5-acetyl-4-hydroxy-2H-1,3-thiazine-2,6(3H)-dione and 2-aminophenol, Spectrochimica Acta Part A: Molecular and Biomolecular Spectroscopy, 95, 2012, 483-490.

[3]. A. Ayman. Abdel Aziz, Abdel Naby M. Salem, Mostafa A. Sayed, Mohamed M. Aboaly, Synthesis, structural characterization, thermal studies, catalytic efficiency and antimicrobial activity of some M(II) complexes with ONO tridentate Schiff base Nsalicylidene-o-aminophenol (saphH2), Journal of Molecular Structure, 1010,2012,130-138.

[4]. G. Gehad. Mohamed, Zeinab H. Abd El-Waha, Mixed ligand complexes of bis(phenylimine) Schiff base ligands incorporating pyridinium moietySynthesis, characterization and antibacterial activity, Spectrochimica Acta Part A, 61,2005, 1059-1068.

[5]. Radhika Pallikkavil1, Muhammed Basheer Ummathur and Krishnannair Krishnankutty. Schiff Bases of Terephthalaldehyde with 2Aminophenol and 2-Aminothiophenol and Their Metal Complexes, Archives of Applied Science Research, 4 (5), $2012,2223-2227$.

[6]. K. Bibhesh. Singh, Anant Prakash, Hemant K. Rajour, Narendar Bhojak, Devjani Adhikari, Spectroscopic characterization and biological activity of $\mathrm{Zn}(\mathrm{II}), \mathrm{Cd}(\mathrm{II}), \mathrm{Sn}$ (II) and $\mathrm{Pb}$ (II) complexes with Schiff base derived from pyrrole-2-carboxaldehyde and 2amino phenol, Spectrochimica Acta Part A, 76, 2010, 376-383.

[7]. G. Gehad. Mohamed, M.M. Omar, Amr A. Ibrahim, Biological activity studies on metal complexes of novel tridentate Schiff base ligand. Spectroscopic and thermal characterization, European Journal of Medicinal Chemistry, 44, 2009, 4801-4812.

[8]. S. Arunachalam, N. Padma Priya, C. Jayabalakrishnan, V. Chinnusamy, Synthesis, spectral characterization, catalytic and antibacterial studies of new Ru(III) Schiff base complexes containing chloride/bromide and triphenylphosphine/arsine as co-ligands, Spectrochimica Acta Part A, 74,2009, 591-596.

[9]. S.R Bhatt Ram, Preparation and Properties of Dinuclear Schiff Base Complexes from Salicylaldehyde and 2-Aminophenol Complexes of $\mathrm{Cu}$ (II), Co (II) and Ni (II) VD, Chemical Sciences Journal, 63,2012.

[10]. Masoud Salavati-Niasari , Seyed Nezamoddin Mirsattari, Synthesis, characterization and catalytic oxyfunctionalization of cyclohexene with tert-butylhydroperoxide and hydrogen peroxide in the presence of alumina-supported $\mathrm{Mn}$ (II), $\mathrm{Co}$ (II), $\mathrm{Ni}$ (II) and $\mathrm{Cu}(\mathrm{II})$ bis(2-hydroxyanil)benzil complexes, Journal of Molecular Catalysis A: Chemical, 268,2007,50-58.

[11]. K. krishnankutty, P. Sayudevi and Muhammed Basheer Ummathur, Metal complexes of Schiff's bases derived from 3-(arylazo)2,4--pentanediones with 2 aminophenol and 2-aminothiophenol J. Serb. Chem. Soc. 72 (11),2007 1075-1084.

[12]. K. Krishnankutty, Muhammed Basheer Ummathur and P. Sayudevi, Metal Complexes Of Schiff Bases Derived From Dicinnamoylmethane And Aromatic Amines, The Journal of the Argentine Chemical Society, 96 - $N^{\circ}$ (1-2), 2008,13-21.

[13]. Anita Sharma, Tushar Mehta and Manish K. Shah, Synthesis and spectral studies of transition metal complexes supported by NObidentate Schiff-Base ligand.Der Chemica Sinica, Pelagia Research Library, 4(1),2013, 141-146.

[14]. E. Akila, M. Usharani and R. Rajavel, Design, Synthesis And Interpretation Of Binuclear Schiff Base Metal Complexes And Their Application; Antibacterial Activity, International Journal of Inorganic and Bioinorganic Chemistry 14, 2012.

[15]. M. B. Fugu, N. P. Ndahi, B. B. Paul and A. N. Mustapha, Synthesis, characterization, and antimicrobial studies of some vanillin Schiff base metal (II) complexes, Journal of Chemical and Pharmaceutical Research, 5(4), 2013, 22-28. 